\title{
Strategic Planning in Public Universities: A Developing Country Perspective
}

\author{
Daniel Ofori (Corresponding author) \\ University of Ghana Business School \\ University of Ghana \\ Tel: +233-244-548-501～E-mail: dofori@ug.edu.gh \\ Esther Atiogbe \\ Institute of Professional Studies \\ Ghana
}

Received: October 26, 2011

Accepted: December 20, 2011 Published: February15, 2012

doi:10.5430/jms.v3n1p67

URL: http://dx.doi.org/10.5430/jms.v3n1p67

\begin{abstract}
This paper presents the results of an empirical study on strategic planning in three public universities in Ghana. It assesses strategy development, the implementation process, the main challenges to strategic planning in public universities, and what their success factors are. Findings indicate that the nature, form, and sophistication of information and communication technology use influenced successful implementation of strategic plans for two public universities. Other results suggested that members of staff perceived strategic planning to be the responsibility of top management; thus, there is little ownership and commitment by academic and other stakeholders.
\end{abstract}

Keywords: Strategy, Strategic planning, Public universities, Tertiary education, Ghana

\section{Introduction and Problem Statement}

Strategic planning in public universities helps top management to align its resources in the most efficient manner necessary for the attainment of strategic milestones and stay competitive (Bain and Company, 2003). Strategic planning is a rigorous and critical brainstorming session used by university authorities to steer the affairs of the university. The utility that public authorities would gain from strategic planning would depend on the capabilities and social capital of the managers involved in the process, as this would provide university authorities with the urge to design effective organisational plans and appreciate the issues surrounding the quality of university services offered. Planning is one of the four managerial work processes in management. Additionally, the type of environment that a public university operates within would influence the type of plans designed (Hewlett, 1999). However, organizations that merely follow the classical planning process will not survive in fluid environments unless they think strategically.

David (2009) opines that the term strategic management is used synonymously with strategic planning. He defines strategic management as the art and science of formulating, implementing, and evaluating cross-functional decisions that enable an organization to achieve its objectives. For Pearce and Robinson (2007), strategic management describes a set of decisions and actions that contribute to the formulation and implementation of plans designed to achieve a company's objectives. Hoskinson, Hitt, Ireland and Harrison (2008) note that activities carried out during the strategic management process are necessary for ensuring that a firm stays competitive and earns above average returns. For Bowman and Faulkner (1997), the strategic management process is an objective and systematic approach for making major decisions in organizations. In strategic management, an attempt is made to organize information in a way that allows effective decisions to be made under conditions of uncertainty suggesting that since the future is unknown organizations should avoid rationalizing a single correct strategy for the business (Pearce and Robinson, 2007).

A steady stream of recent management literature has encouraged business executives to subscribe to the practice of strategic planning. These advocates argue that the essence of strategic planning is to provide an organisation with a game plan whilst also enabling it to match its capabilities and competencies to competitive conditions of the external environment (David, 2009; Philips and Appiah-Adu, 1998). Thus the development of a well-conceived strategic plan 
would enhance business performance. This notion has caught the attention of both academics and executives and brought about a greater focus on integrating and optimizing management processes through strategic planning.

Tertiary education in Ghana dates back to the early 19th century when colleges were established (in the then Gold Coast) to provide education from kindergarten to university (http:www.bc.edu/bc_org/avp/soe/cihe.htm). The University College of Gold Coast now University of Ghana was established in 1948 forming a special relationship with University of London (Agbodeka, 1998). Over the years, other tertiary institutions were established. Public universities enjoyed much government support for the most part of the 1960s through the mid 1970s but were confronted with several problems as a result of severe economic challenges in Ghana. By the mid 1980s, structural reforms imposed on the country by the International Monetary Fund and World Bank had taken their toll on tertiary institutions as they favoured basic and secondary education whilst tertiary education took a backseat.

Consequently, the effectiveness and efficiency of Higher Educational Institutions (HEIs) suffered over the years, especially during the 1990s as they became inhibited by numerous challenges. Perhaps, among the most serious challenges that public universities faced, were inadequate funding and rising student populations without the commensurate increase in infrastructure (www.bc.edu/bc_org/avp/soe/cihe/profiles/Ghana.htm). Over the years, globalization and the growth of the population have proved to be a great challenge to these universities to the extent that their original purposes needed to be modified to avert the inevitable. These challenges tend to affect the quality of higher education and have a negative effect on the overall national development. Available statistics show that enrolment in the six public universities in Ghana increased by 165\% from 11,857 in 1991-92 to 31,460 in 1998-99 and the number of qualified applicants received within this period also experienced a sharp increase (www.bc.edu/bc_org/avp/soe/cihe/profiles/Ghana.htm).

In contrast to the increase in enrolment, academic and other infrastructure in HEIs in Ghana have not seen much improvement and expansion since their establishment. Furthermore, as a result of poor conditions of service, HEIs have not been able to attract and retain academic staff. Indeed, a study by Manuh, Asante and Djangmah (2005), showed that $40 \%$ of academic staff would have retired from higher learning institutions within a period of ten years. Compounding this problem is the fact that the rate at which academic staff is being replicated through the training of postgraduates is extremely low and further hampered by the difficulties in recruiting experienced faculty internationally. Meanwhile, the manpower needs of government as well as those of industry have undergone significant changes in response to the rapid development in their operating environment.

Several challenges are currently driving public universities in Ghana to examine the way they operate: ability to survive in the 21st Century and beyond; coping with new models in the provision of higher education; addressing the competitive issues spawned by the rise of private universities; and a growing imperative to provide quality human resources to meet national developmental needs. These challenges have become increasingly daunting and the antidote seems to lie in the use of strategic planning. In this regard, strategy can only make a difference when the intended purposes of the public universities are aligned to action and they can adequately respond to emerging internal and environmental issues. This would require greater flexibility, agility and the capacity to adapt to change, all of them issues that form the prime task of strategic management.

\subsection{Objectives of the Study}

The study therefore sought to carry out a comparative evaluation of strategic planning in public universities in Ghana and to examine the flexibility of the resulting strategic plans in the face of emerging challenges.

Specifically, the study's objectives were to:

- Examine the nature of the strategic planning process within public universities in Ghana

- Investigate how strategic plans are implemented within public universities and assess their success or otherwise.

- Identify and analyze the problems and challenges attending strategic planning in public universities and

- Recommend appropriate measures and best optimizing practices for the performance of public universities in Ghana.

\subsubsection{Hypotheses}

The research is hinged on the following premises;

- Institutional culture and information communication technology (ICT) are key for successful implementation of strategic plans of public universities in Ghana 
- $\quad$ Effective mobilization and management of financial resources will lead to better performance in public universities in Ghana.

\subsubsection{Significance of the Study}

The study will serve as a strategic management framework for further research by faculty and students. Practitioners and strategic management consultants of public universities would find the study particularly useful in their line of work as they attempt to resolve public universities' planning issues. Additionally, policy makers and stakeholders would find the study especially useful in the decision- making process. It would also contribute in addressing the gaps in knowledge on strategic planning especially within public universities in Ghana and serve as a reference point for the general public.

\section{Literature Review}

Strategic planning is a sequence of analytical and evaluative procedures to formulate an intended strategy and the means of implementing it and staying competitive (Nicolae, 2008; Mintzberg, 1994; Johnson and Scholes, 1999). For Mintzberg, Ahlstrand and Lampel, (1998) even though the strategic management literature is replete with a myriad of strategic planning models, certain basic ideas are common to all; formal procedure, training, analysis and lots of numbers to be guided and led by a learned group of planners who are part of a specialized strategic planning department, with access to the chief executive.

\subsection{The Nature of Strategic Management and Strategic Planning}

Central to strategic management is the determination of long-term goals and objectives of an organization serving as a framework within which choices are made concerning the nature and direction of the organization (Stoney, 2001; O’Regan and Ghobadian, 2002; David, 2009). This framework helps in the allocation of resources in order to enhance financial and strategic performance (Bain and Company, 2003). By "nature " and "direction” implies that decisions are of fundamental importance to the organization as opposed to less important, operational decisions. Strategic management also places emphasis on resource allocation and plans throughout the entire organization (Dincer, Tatoglu and Glaister, 2006). From this perspective, strategy is considered as a deliberate planning process, initiated by top management, based on an elaborate industry analysis and aimed at designing a cohesive grand strategy for the organization (Dincer, et. al., 2006). Strategic management further ensures that the organization has appropriate structures, processes and culture or mindset, to carry through a programme of change (Stoney, 2001).

Strategic planning has also been described as a formal managerial process. Shaw, Brown and Bromiley (1998) indicated that it can be broadly defined as the process of determining the mission, major objectives, strategies, and policies that govern the acquisition and allocation of resources to achieve organizational aims. To Johnson and Scholes (1999), strategic planning is a systematic analysis and evaluation of procedures to formulate strategy as well as the process of implementing that strategy. Also Strategic planning can be considered from a content or process point of view (O’Regan and Ghobadian, 2002). The content relates to the distinct elements of the strategic plan which differ for every organization and the process relates to the mechanisms for the development of the strategic plan and its subsequent deployment.

The thrust of this study is that strategic planning is a key aspect of strategic management that deals with the integration of the organization's major goals, policies and action sequences into a cohesive and coherent whole (Stoney, 2001). It is therefore the set of processes undertaken to develop a range of strategies that will contribute to achieving the organizational direction.

To achieve competitive advantage, a steady stream of management literature encourages business executives to subscribe to the practice of strategic planning. These advocates argue that the essence of strategic planning is to match an organization's capabilities and competencies to competitive conditions of the external environment (David, 2009; Philips and Appiah-Adu, 1998). This suggests that the development of a well-conceived strategic plan across strategic businesses would enhance business performance, and for that matter the performance of public universities in Ghana though they are not set up to make profit. Furthermore, management researchers have encouraged executives to consider the merits of strategic planning and, with few exceptions, theorists in the field have advanced the view that planning is a critical management activity (David, 2009; Appiah-Adu, Morgan and Katsikeas, 1996).

Grant (2003) also notes that empirical research in strategic planning systems has focused on two areas: the impact of strategic planning on firm performance and the role of strategic planning in strategic decision-making. Prescriptive writings in this area suggest that planning may significantly contribute to effective decision making, appropriate allocation of resources and the long-term organizational prosperity of the firm (Duncan, 1990; Lombardi, 1994). Effective strategic planning clearly requires defined achievable goals, systematic integration of a number of sequential activities, and above all commitment to implement the plan. There is no doubt that a well-conceived plan can be an effective catalyst for managing change and enhancing decision-making processes in organizations. 
Whilst some writers consider strategic planning as a part of the strategic management process, David (2009) notes that the term strategic management is used synonymously with strategic planning. However, there seems to be a general agreement that there are three components of strategic planning, namely - formulation, implementation and evaluation (Pearce and Robinson, 2007; Hopkins and Hopkins, 1997; Johnson and Scholes 1999; David, 2009). Thus, a well crafted strategy must also be well executed and monitored to ensure that the objectives are achieved.

\subsubsection{Traditional Strategic Planning Models}

According to Mintzberg et al, (1998), the basic strategic planning model originated from Ansoff (1965; 1987: p 37), the Harvard Group and Steiner (1979) asserting that strategic planning reached its peak in the 1970s when managers extolled the virtues of formal strategic planning. This basic model involves five stages which are objective setting, external and internal auditing, strategy evaluation and operationalization stages. In this model there is also programming of works where a plan of action regarding how, where and what needs to be done is drawn to ensure that the process is achieved on time. This model has been criticized to be too rational and methodical with a long hierarchy of activities making it bureaucratic and may not succeed in dynamic, changing environments (Chaffee, 1985). However, it remains the basic building blocks upon which strategic planning is developed in almost all situations.

The second traditional model known as the HAX model was developed by Hax (1990). It is said to be a rational approach in which activities in developing a strategy flow in a sequential manner. He derived the model from the various hierarchical levels that exist in the organization emphasizing that their different managerial responsibilities contribute to defining the strategy of the organization. In his discourse, he indicated that three levels of strategy exist in an organization - corporate, business and functional levels. He argued that, the general tasks that need to be addressed are the responsibility of corporate level strategists and these primarily include the determination of overall missions, validation of proposals emerging from business and functional levels, identification and exploration of linkages between distinct but related business units, and the allocation of resources with a sense of strategic priorities.

The second level, intrinsic to the business unit, is the place where the activities needed to enhance the competitive position of each business unit is coordinated. The third level, functional level, deals with competency development such as financing, administrative infrastructure, human resources, technology, logistics, etc. Hax (1990) concludes that regardless of the structure adopted by a firm, these three highly differentiated strategic concerns still remain. These two models have been referred to in the literature as the linear approach to strategy because it connotes the methodical, directed, sequential action involved in planning (Chaffee, 1985).

\subsubsection{A Dynamic Approach to Strategic Planning}

Spotting problems early as a result of close monitoring of the environment is core to dynamic strategic planning. Effective implementation of strategy is essential to its success (McGuinness and Morgan, 2005; David, 2009). However, there is evidence in the strategy literature about it being neglected and ill-conceived (Piercy, 1998; Noble and Mokwa, 1999; Sashittal and Jassawalla, 2001; Kennedy et al., 2003). In particular, Noble and Mokwa, (1999) believe that the nature of implementation and why it succeeds or not have not been well understood.

For McGuinnes and Morgan (2005), in this timeless framework, strategic planning's main themes are strategy formulation and implementation, which are treated separately and sequentially. They further state this traditional, linear approach emphasizes the design of organizational structures and systems; that implementation is an administrative issue and follows after formulation as day follows night.

Cespedes and Piercy (1996, p.138) have referred to the formulation-implementation dichotomy as the heart of the traditional approach stating that the many difficulties that arise in the practice of implementation can be attributed to it. To resolve this problem a different mix of skills and abilities are needed (McGuinnes and Morgan, 2005) and to this end they propose three themes. These are a process perspective on implementing strategy, an emergence view and co-aligning the organization with its environment.

A process perspective of implementing strategy (Piercy, 1998; Noble, 1999) widens the traditional focus on organizational structure and control systems by also including behavioural and interpersonal process elements (McGuinnes and Morgan, 2005). This they said, would introduce psychological issues such as individual motivation and commitment; and issues relating to social and political processes such as organizational culture, leadership, and learning which requires consideration as a result of their complex interrelationships with organizational structure and control systems. An emergence view of strategy deliberately puts formulation and implementation together (McGuinnes and Morgan, 2005). They are viewed from this perspective as interactive and reciprocal processes, intertwined in a higher level process of strategy emergence, adaptation and improvisation (Moorman and Miner, 1998; Sashittal and Jassawalla, 2001). 
The third theme that McGuinnes and Morgan (2005) propose towards solving the formulation-implementation problem is co-alignment of the organization with its environment as a process indicative of strategic intent; noting that it involves the purposeful, adaptive coordination of organizational goals and actions over time. This is an essential part of the dynamic concept of strategy. These themes, they argue, provide a coherent basis for formulating and implementing strategy.

Supporting the foregone, Parnell, (2006) and Feurer and Chaharbaghi (1997) argue that no single strategy process or single strategic capability will lead to a sustainable competitive advantage. Organizations, therefore, must necessarily adjust their characteristics dynamically as conditions in the environment change. To succeed, organizations need to choose from a wide range of strategic capabilities instead of depending on specific aspects only. The role of strategists has to change from that of planners and strategy creators to that of strategy finders, knowledge generators and catalysts of change and that strategic planning must be replaced by strategic thinking (Mintzberg, 1994; Massingham 2004; Snyman and Kruger, 2000). This is supported by Abraham (2005) who notes that strategic thinking is finding alternate ways of competing and providing customer value. Therefore the classical understanding of strategic planning must be replaced by a more dynamic understanding that focuses on strategic issues. In this regard, McGuinness and Morgan (2005) advocate that organizations should not dwell on past successes only but also focus on new concepts, creativity and strategy innovation; adopt a systems thinking approach to strategy development and give attention to business process redesign in the context of strategic change.

In a nutshell, in dynamic environments, the increasing complexity of business issues require the close-cooperation of people from different areas and functions within the organization in order to optimize the use of the knowledge base that is available in addressing the issues and enhance the level of creativity in the development of solutions. High performance in dynamic environments is a characteristic that must be constantly pursued through an ongoing process of change which is in line with changes in the competitive environment, the values of the organization and its capabilities.

\subsection{The Strategic Planning Process}

The strategic planning process, which can be formal or informal, entails setting visions and missions, goals and objectives; clarifying policies and principles; and searching for opportunities, threats, strengths and weaknesses (SWOT). One of the critical aspects of being successful in a modern business context is having a clear vision, a balanced journey for the future based on a market-oriented approach and building core competencies of the organizations concerned. Whether developing a new business or reformulating direction for an ongoing company or institution, the basic goals, characteristics and philosophies which will shape a firm's strategic posture must be determined (Pearce and Robinson, 2005). The mission guides future executive action. Thus a company mission can be defined as the fundamental, unique purpose that sets a business apart from other firms of its type and identifies the scope of its operations in product and market terms (Pearce and Robinson, 2005). The principal value of a mission statement is the specification of the ultimate aims of the firm and which also provides managers with a unity of direction that transcends individual, parochial and temporary needs.

As Lynch (1997) notes, long term objectives are the results a business seeks to achieve over a specified period of time, typically five years. Seven common long-term objectives he describes are; profitability, productivity, competitive position, employee development, employee relations, technological leadership and public responsibility. These and any other term objectives should be acceptable, flexible, and measurable over time, motivating, suitable, understandable and achievable. Policy and strategy has to be tackled as a whole process which needs to be managed and reviewed on a regular basis. Objectives could be short-term, medium-term or long-term.

Strategic planning involves carefully analyzing the external environment, because the environment keeps changing and calls for new organizational strategies (Beal, 2006). The aim is to produce a documented picture of the most significant environmental developments around which the organization must formulate its future goals, strategies, structures and systems. Second, the internal scan or assessment of the internal environment of the organization involves identification of its strengths and weaknesses, that is, those aspects that help or hinder accomplishment of the organization's mission and fulfilment of its mandate with respect to People (Human Resources), Properties (Buildings, Equipments and other facilities), Processes (Such as student placement services, M.I.S etc.), Products (graduates, Publications etc.) [http://www.agecon.purdue.edu/staff/gray/Extension/strategic\%20Planning/internal.ppt.] A SWOT analysis is conducted with a focuses on the internal and external environments, examining strengths and weaknesses in the internal environment and opportunities and threats in the external environment.

\subsubsection{Strategy Implementation}

In their search for sustainable advantage, researchers have realized that business performance is not concentrated on the 
formulation alone but also on the implementation of a given strategy and further strengthened by the processes by which competitive positions are created and maintained (Feurer and Chaharbaghi, 1997). For Griffin (2004), strategy implementation is the method by which strategies are operationalized or executed within the organization. It focuses on the processes through which strategies are achieved.

Once the means and methods for achieving objectives and mission have been identified, the next step according to Alashloo, et al, (2005) is to begin "doing”. This stage involves the continuation of some ongoing strategies as well as the beginning of some new strategies (Brewer et al., 2000). As a result, managers should consider analysis of organizational structures and systems before strategy implementation, as well as the analysis of culture, power and conflict (Ellis and Dick, 2000). To effectively implement and manage the strategy, managers must integrate the activities of several different functions. These activities help to achieve the best integration of people, structures, processes and resources in reaching organizational purposes.

\subsubsection{The Concept of Evaluation}

The final stage of strategic planning is the evaluation stage. It is incumbent on management to evaluate the strategy and the organization's performance and progress. It is management's duty to stay on top of the stakeholder situations, deciding whether things are going well internally and monitoring outside developments closely. Evaluation is a way of consolidating lessons and a way of synthesizing prior experience (Mark, 2005). The interest in evaluation theory and practice is linked directly to the expansion of government programmes during the 1903s in the United States (Smith, 2001; 2006), and particularly in the 1980s in Ghana. Evaluation is an issue that has steadily risen up the agenda for governments and other entities where large state money has flowed into projects and programmes. Officials have sought therefore to increase monitoring and review as a way of assuring effectiveness and efficiency (Smith, 2001; 2006). Evaluation has therefore become a contemporary concern owing to the growing demand for verification of programme results.

The theory of evaluation has three broad dimensions - positivist, constructivist and realist approaches. The positivist approach advocates developing a hypothesis, collecting primarily quantitative data, and using this to test the hypothesis and evolve a theory so that cause and effect relationships are established (McCoy and Hargie, 2001). The constructivist approach focuses on the need to explore the way in which people make sense of their experiences. Thus it was designed to be responsive to the characteristics of the programme environment and the issues identified by stakeholders (McCoy and Hargie, 2001). The realist approach assumes that the evaluator already has a theory about what works, for whom, in what circumstances, and why, and will use this to design the research (http://www.weresearchit.co.uk.evaluation_theory.htm).

From the realist approach, evaluation is the systematic exploration and judgement of working processes, experiences and outcomes. It pays special attention to aims, values, perceptions, needs and resources (Smith, 2001; 2006). Evaluation is also the ability to prove that something is working or needed, or improving practice (Rogers and Smith 2006). Underlying these definitions is accountability. The need and desire for accountability presents the need for evaluation. It can also be inferred that accountability is not a limiting activity, rather, a design that improves and makes programmes better. It is the belief that goals and objectives be developed and specified in social terms as a prerequisite to evaluation (McCoy and Hargie, 2001). Furthermore, the potential for feedback of results while the programme or strategy is underway is at the centre of ongoing evaluation.

It is important to evaluate because funders need to be assured that their resources are being used efficiently and making great impact. It also makes those leading the programme/strategy better communicators so that issues can be resolved before they reach a crisis level (Anderson and Kleiner, 2003). Evaluation is therefore effective if it is built into the planning process. The rapid accelerating change of the global market place of the last few years has made continuous improvement another important aspect of strategic control in many business organizations (Pearce and Robinson, 2002). They emphasize that this is synonymous with total quality improvement (TQM) which provides a way for the organization to respond more proactively and timely to rapidly changing developments in areas that influence business success.

The choice of whether to continue or change the company's vision, objectives, strategy, and implementation approaches always presents itself. Strategic management is an ongoing, never-ending process, not a start-stop event that, once done, can be safely put aside for a while. Therefore, custodians of a strategic plan have an ever-present responsibility for detecting when new developments require a strategic response and when they do not. Their job is to track the progress, spot problems and issues early, monitor the environment and initiate adjustments as needed (Thompson and Strickland, 2001). 


\section{Methodology}

The study adopted an exploratory and comparative methodological approach in examining the nature of strategic planning in public universities in Ghana. The exploratory approach was used because it appears little is known about the form, nature and type of strategic planning done in public universities in Ghana.

The multi-stage sampling technique was used in this study. In the first stage purposive sampling methods were used to select three public universities in Ghana for the survey which was conducted between March and September 2007. The three public universities involved in the study are the earliest to be established in Ghana as well as the largest in terms of student enrolment. Thus their structures might have been well formed and their experience could adequately represent the nature of strategic planning in the public universities in the country. As regards the universities themselves, the oldest one(University of Ghana) was selected because its governance arrangements have been the model for most of the other universities in the country. It was in the same vein that the second and third oldest and largest universities, (the Kwame Nkrumah University of Science and Technology [KNUST] and the University of Cape Coast [UCC]) were selected.

In the second stage a stratified sampling method was used to select sources of the data. This approach was used to obtain a balanced data from key stakeholders of the universities. Thus, management, central administration, provosts, deans, head of departments, students, workers and faculty constituted various strata.

The last stage involved the use of a purposive sampling technique again to select members from each stratum to constitute the sample size. This technique was used because even in each stratum, not all members have knowledge of the strategic planning processes and systems of their respective universities.

Previously piloted questionnaires were then distributed to key members selected from the various strata. This was supplemented by structured interviews with key respondents from management, central administration, provosts, deans and heads of department. The items in the questionnaire were used to measure the following variables of interest in the study - the nature of strategy formulation, the strategic planning process, strategy implementation and the extent of a wider value system; the evaluation of strategic planning; the extent of effectiveness of strategic planning and the challenges of strategic planning in public universities.

The questionnaires were self-administered by the researchers and this gave them the opportunity to probe further on responses and also offer explanations to the questions that seemed ambiguous to respondents. In all 150 questionnaire were administered and 100 were received for analysis, giving a return rate of about $66 \%$. In addition to the primary data, secondary data were used for the study. These include information from documents such as brochures, strategic plans, charters, legislations, statutes and journals obtained from the universities as well as regulatory authorities like the Ministry of Education, National Council for Tertiary Education and the National Accreditation Board.

\subsection{Data Analysis and Results}

Quantitative data was analysed with the Statistical Package for Social Sciences (SPSS) and Microsoft Excel software and results presented in frequency tables, diagrams and figures. Analysis of variance (ANOVA) and regression analysis were used to determine the relationships and the variations between and amongst the different groups.

\subsubsection{Discussion of Empirical Findings}

The study revealed that all the universities studied practice the two models of strategic planning, the basic strategic planning model and the Hax Model, engaged in situational analysis and followed due best practice, that is, issues in the external and internal environments were properly analyzed. Thus, the universities were vigilant in identifying the strengths, weaknesses, opportunities and threats in the environment. This led to the determination of the missions, goals, objectives and action plans to be undertaken implying effectiveness for all the universities, though two of them (the University of Ghana and Kwame Nkrumah University of Science and Technology) showed more effectiveness. Furthermore, the study revealed that there is considerable competition between the public universities such that programmes that were hitherto abandoned by some universities are being reintroduced and all of them had and continue to introduce programmes that appeal to specific groups in their communities.

The study also revealed that quite a large number of respondents are aware of strategic planning in their university. Strategy development in the public universities is formal and linear indicating that decision making is top-down involving mostly higher and middle management as against members of lower management and other stakeholders in sync with (Chaffee, 1985). For some respondents the non-involvement of the other stakeholders was because they were regarded as "incapable" (especially junior and senior staff) since this group lacked adequate training. The level of top and middle management involvement was consistent with all the universities covered. This lack of full coverage may not ensure ownership and commitment of the strategic planning process throughout the university but only among those considered 'capable', that is, at the top. 


\subsection{Strategy Implementation and its Success within Public Universities}

For an implementation process to be effective, an organizational structure must be suitable or relevant to the current strategy. With the structure following strategy principle, it was observed that the universities had indeed adjusted their organizational structures to aid the implementation process to a large extent. One university (the University of Ghana) had re-organized all the academic units into colleges whilst the other two are doing so systematically in an action meant to decentralize decision-making from the centre. However, the intention to professionalize the administrative professions and review their functions had not been very effective.

An attempt was made to probe into the existence of values that culminate in a culture of excellence within the universities under study. Overall it was found that the values that existed in the universities do not effectively inform the behaviours of the members of these institutions. They only existed in name as leadership had not effectively ensured that an excellent culture was understood and shared by all. Respondents unanimously agreed that culture is a driving force for implementing strategy but in their opinion, leadership was not setting the right example. As regards the working of the committee system it was found that administration throughout the universities encouraged participation which indeed, served as a leveraging tool for building and sustaining a workable culture. Comparatively, UCC was more effective than KNUST which was more effective than UG in this regard.

Another factor considered significant to strategy implementation is resource allocation. A cross-tabulation of multiple responses from the various institutions revealed that allocation of resources mostly depended on the number of students enrolled in an academic year, (93\%). The second factor was the extent of research work undertaken (11\%). A tenth (10\%) of the respondents indicated that it resource allocation depended on effective teaching time; whilst $11 \%$ of the respondents indicated various other means of allocating resources in their individual university. The findings further revealed that resource allocation (financial) in all three universities was not effective mainly due to inadequate funding. Though the universities have resorted to redesigning activities in the finance units through the ITS system, the change aspects were not properly configured due to inadequate personnel numbers and a lack of expertise.

However, evaluation of strategic planning across all three universities is done by a dedicated team. There are monitoring and controlling systems in the areas of finance, admissions, examination questions and declaration of results as well as monitoring of performance of staff. Monitoring, evaluation and control enable decision-makers to keep track of planned actions and monitor and compare the actual performance of policies and programs with the anticipated performance target. The process permits the necessary corrective measures to be taken and this should be done as frequently as possible by the public universities to take full advantage of the positive outcomes.

\subsubsection{Factors contributing to successful strategic planning in public universities}

Several hypotheses were tested under this section; with the first hypothesis addressing the issue of whether institutional culture and ICT are key for the successful implementation of strategic planning in public universities. A multiple regression analysis indicated that institutional culture as practiced at the University of Cape Coast (UCC) is not key to successful strategy implementation $(0.06 \%$ or $\mathrm{r} 2=0.0057)$ and $\mathrm{P}>0.91$. An improvement in the culture will lead to a very small improvement in successful strategy implementation, where $(r=0.025)$.

With regard to ICT, a 10.5\% success rate of strategic plan implementation is explained by the effect of ICT introduction where $\left(r^{2}=0.1047\right)$ and $\mathrm{P}>0.11$. Thus, an improvement in ICT leads to an improvement in successful strategy implementation where $(r=0.0323)$ as shown in Figures 1 and 2 below. As a single factor, ICT had a better influence on successful implementation of strategy than institutional culture but together the hypothesis was not supported in the case of the University of Cape Coast (UCC).

In the case of the University of Ghana (UG) the regression showed a 76\% success rate in strategy implementation explained by the institutional culture practiced where $\left(\mathrm{r}^{2}=0.7595\right)$ and where $\mathrm{P}=0.05$. There is therefore an association between institutional culture as practiced at UG and the success of strategy implementation $35 \%$ of the time where $(r=$ 0.35).

On the other hand, the regression showed only a 7.6\% success rate in strategy implementation as a result of the introduction of ICT where $\left(\mathrm{r}^{2}=0.076\right)$ and $\mathrm{P}>0.30$. Thus, ICT is negatively correlated with successful strategy implementation where $(r=0.1119)$, see Figures 3 and 4 below. As a single factor, institutional culture has a better influence on successful strategy implementation than ICT but together the hypothesis is not supported in the case of the University of Ghana (UG).

At the Kwame Nkrumah University of Science and Technology (KNUST), the regression showed a 95\% success rate on strategy implementation due to the presence of institutional culture, where $\left(r^{2}=0.9505\right)$ and $\mathrm{P}<0.008$. An association between institutional culture and successful strategy implementation occurs $39 \%$ of the time where $(r=0.386)$. 
As regards ICT, the regression analysis indicates that $37.5 \%$ of successful strategy implementation is explained by the institutional culture practiced where $\left(\mathrm{r}^{2}=0.3758\right)$ and $\mathrm{P}>0.54$. Thus, there is a positive association between ICT and successful strategy implementation $1.4 \%$ of the time where $(r=0.0137)$ see Figures 5 and 6 below.

Therefore, in terms of the influence of institutional culture and ICT on the success of strategic planning implementation, there is greater influence on the University of Ghana, than the University of Cape Coast, which is in turn greater than the Kwame Nkrumah University of Science and Technology. Thus the hypothesis is fully supported only in the case of the University of Cape Coast (UCC).

\subsubsection{Effective mobilisation and management of financial resources leads to better performance}

The second hypothesis postulated that effective mobilization and management of resources will lead to better performance. Respondents in each of the three universities equally perceived that an effective mobilization and management of resources would result in better performance where r2 $=1$ is shown in Figure 7 below. Thus the hypothesis was supported by $100 \%$ of the respondents in all the three universities.

The fact that there is a lack of funding implies that university authorities must necessarily mobilize financial resources (a stated objective) and also manage available funds (especially internally generated income) judiciously and efficiently to ensure successful implementation of strategic plans. Resource mobilization should be an activity that should constantly complement strategic planning; therefore, new or additional resources must be mobilized including people, goods and services. It is important to identify strategy-critical activities that create value for the universities and direct efforts to achieve them while making better use of available resources.

A ranking of factors gleaned from interviews indicated that in addition to institutional culture and ICT respondents noted that other building blocks of success for their institutions stemmed from effective leadership as well as available capable and competent human resources. In benchmarking the views from all three universities against each other, it was observed that responses were ranked equally by the respondents. These findings support Porter's (1980) opinion that industry competition is determined by benchmarking how a company performs a specific activity against those of their competitors.

The ultimate objective of benchmarking is to identify "best practice" in performing a particular activity and learn how lower costs and other outcomes linked to excellence can be achieved. Therefore, the public universities under study need to improve on the other factors that are equally important for success especially ICT and infrastructure. In the integrated approach to strategic planning, McGuinness and Morgan (2005) advocate a focus on creativity and innovation and adoption of a systems approach. Thus public universities need to consider how their strategic planning activities impact their clientele through the feedback loop within their learning and cognitive processes. Feurer and Charharbaghi (1997) also emphasize speed as an integral part of strategic planning leading to the generation of large strategic options in line with changes occurring in the competitive environment. In other words, high performance in dynamic environments is an imperative that must be pursued through an ongoing process of change which is in line with changes in the competitive environment of the public universities.

\subsection{Other Challenges Affecting Strategic Planning in Public Universities in Ghana}

The study also identified a number of challenges affecting strategic planning in Ghanaian public universities. Notable amongst them are inadequate funding from government that ultimately inhibits access to needed logistics to carry out programmes; poor work culture among members of the university; unwillingness by leaders to listen to comments and suggestions (avoiding downward communication); a lack of appreciation of work done well; and a lack of well defined appraisal systems. Other challenges include lack of motivation and lack of investment in ICT to support the planning process. With regards to motivation, all three universities performed poorly but the KNUST was the least effective followed by UCC and UG, in that order.

\section{Conclusions}

Based on the forgoing, the following conclusions may be drawn from the study:

- $\quad$ The public universities have adopted a linear approach to strategic planning therefore, not many people owned the strategic plans.

- $\quad$ Consequently, the implementation process lacked the support of all stakeholders, implying that the process is not working for the universities. Also, organizational, managerial and individual issues impede the process of implementation. In spite of the challenges identified there is some level of success, with the KNUST doing better than the UG and UCC. 
- Indeed, to ensure success for future planning the integrated approach should be adopted by public universities where a wider value system is emphasized to empower those leading the strategic planning process.

\section{Recommendations and Further Research}

The study recommends the adequate resourcing and funding of Ghanaian public universities by the government, as well as alumni and the granting of more autonomy to authorities to charge economic fees. For a higher level of strategic planning competence, the leaders (university administration) should be more adaptive and reduce hierarchical elements to a minimum. The adoption of the collegiate system of governance and the attraction and retention of young competent teaching staff are also recommended.

Future studies could cover all the six public universities in Ghana as well as comparing strategic planning in public and private universities.

\section{References}

Abraham, S. (2005). Stretching Strategic Thinking. Strategy and Leadership, Vol.33, No. 5, pp.5-12. http://dx.doi.org/10.1108/10878570510616834

Agbodeka, A. (1998). A History of University of Ghana: Half a Century of Higher Education (1948-1998), pp.24; 123-124.

Alashloo, F. R., Castka, P., and Sharp, J. M. (2005). Towards Understanding the Impeders of Strategy Implementation in Higher Education (HE), A Case of HE Institutes in Iran. Quality Assurance in Education, Vol. 13, No. 2, pp.132.-147.

Anderson, B., and Kleiner, B.H. (2003). How to Evaluate the Performance of Chief Executive Officers Effectively, Management Research News, Vol. 6, pp. 3.-11.

Ansoff, H. I. (1965). Corporate Strategy, McGraw-Hill, New York.

Ansoff, H. I. (1987). The Emerging Paradigm of Strategic Behavior, Strategic Management Journal, No. 8, pp. 501.-515.

Appiah-Adu, K., Morgan, R.E., and Katsikeas, C.S. (1996). Diagnosing Organizational Planning Benefits: The Efficacy of Planning Formalization, Journal of Strategic Marketing, Vol. 4, pp. 221.-238.

Bain and Company. Bain Study Reveals How Firms are Using Three Main Analytical Tools, Financial Times, No. 4.

Beal, R. M. (2006). Competing Effectively: Environmental Scanning, Competitive Strategy and Organisational Performance in Small Manufacturing Firms, Journal of Small Business Management. Vol. 38.No. 1, pp. 27.-47.

Bowman, C., and Faulkner, D. (1997). Competitive and Corporate Strategy. Times Mirror International Publishers Limited, London.

Brewer, P.D., Brewer, V.L., and Hawksley, M. (2000). Strategic Planning for Continuous Improvement in a College of Business, The Mid-Atlantic Journal of Business, Vol. 36, No. 2-3, pp. 123-32.

Cespedes, F.V., and Piercy, N.F. (1996). Implementing Marketing Strategy, Journal of Marketing Management, Vol.12, pp. 135.-160.

Chaffee, E. E. (1985). Three Models of Strategy, The Academy of Management Review, Vol.10, No.1, pp. 89-98

David, F. (2009). Strategic Management: Concept and Cases, $12^{\text {th }}$ Ed., Prentice Hall, NY.

Dincer, O., Tatoglu, E., and Glaister, K.W. (2006). The Strategic Planning Process: Evidence from Turkish Firms, Management Research News, Vol.29, No.4, pp. 206-219. http://dx.doi.org/10.1108/1409170610665068

Duncan, H. (1990). Strategic Planning Theory Today, Optimum, Vol. 20, No.4, pp. 63-74.

Ellis, S., and Dick, P. (2000). Introduction to Organizational Behaviour, McGraw-Hill, London.

Fuerer, R., and Chaharbaghi, K. (1997). Strategy Development: Past, Present and Future, Training for Quality, Vol.5, No.2, pp. 58-70. http://dx.doi.org/10.1108/09684879710167647

Grant, R.M. (2003). Strategic Planning in a Turbulent Environment: Evidence from Oil Majors, Strategic Management Journal, Vol.24, No.2, pp. 491-517. http://dx.doi.org/10.1002/smj.314

Griffin, R. W. (2004). Management, Houghton Mifflin Company, U.S.A., pp.202. 
Hax, A. C. (1990). Redefining the Concept of Strategy and the Strategy Formulation Process. Strategy and Leadership, MCB UP Limited, Vol 18, Issue 3, pp.34-39.

Hewlett, C. A. (1999). Strategic Planning for Real Estate Companies, Journal of Property Management, Vol.64, No.1, pp. 264.

Hoskinson,, R. E., Hitt, M. A., Ireland, D. and Harrison, J. S. (2008). Competing for Advantage, Second Edition. Thomson Higher Education

Johnson, G., and Scholes, K. (1999). Exploring Corporate Strategy, 5th Edition, Prentice Hall, pp.11-13; $23 ; 25$.

Kennedy, P., Perrottet, C., and Thomas, C. (2003). Scenario Planning after 9/11: Managing the Impact of a Catastrophic Event, Strategy and Leadership, Vol 31. Issue 1.

Lombardi, D. J. (1994). Chain-Restaurant Strategic Planning, Cornell Hotel and Restaurant Administration Quarterly, Vol.35, No.3, pp.38.

Lynch, R. (1997). Corporate Strategy Financial Times, Pitman, London, pp.179.

Manuh, T., Asante, R., and Djangmah, J. (2005). At Home in the World? The Brain Drain in the Higher Education Sector in Ghana, Sub-Saharan Publishers, Accra, pp. 251-277.

Mark, M. (2005). Evaluation Theory or What are Evaluation Methods For? The Evaluation Exchange, Vol. XI, No.2, pp. $1-4$.

Massingham, P. (2004). Linking Business Level Strategy with Activities and Knowledge Resources, Journal of Knowledge Management, Vol.8, No.6, pp. 50-62. http://dx.doi.org/10.1108/13673270410567620

McCoy, M., and Hargie, O.D.W. (2001). Evaluating Evaluation: Important Implications for Assessing Quality. International Journal of Health Care Quality Assurance, MCB UP Limited, Vol. 14, No. 7, pp. 317-327.

McGuinness, T., and Morgan, R.E. (2005). The Effect of Market and Learning Orientation on Strategy Dynamics: The Contributing Effect of Organizational Change Capability, European Journal of Marketing, 39(11/12), pp. 1306-1333. http://dx.doi.org/10.1108/03090560510623271

Mintzberg, H. (1994). Rethinking Strategic Planning Part I: Pitfalls and Fallacies, Long Range Planning, Vol. 27, No.3, pp. 12-21. http://dx.doi.org/10.1016/0024-6301(94)90185-6

Mintzberg, H. (1994). The Rise and Fall of Strategic Planning, Harvard Business Review, Vol. 72, No.1, pp. 107-114.

Mintzberg, H., Ahlstrand, B., and Lampel, J. (1998). Strategy Safari: A Guided Tour through the Wilds of Strategic Management, The Free Press, New York, pp. 9-15.

Moorman, C., and Miner, A. S. (1998). The Convergence of Planning and Executing: Improvisation in New Product Development, Journal of Marketing, Vol.62, pp. 1-20. http://dx.doi.org/10.2307/1251740

Nickols, F. (2000). Strategy: Definitions and Meaning, Distance Consulting, pp.1.

Nicolae, I. (2008). Strategic Management in Nonprofit and Public Organistions, Management and Marketing Journal, Vol 6, Issue 1, pp. 185-191.

Noble, C.H. (1999). The Eclectic Roots of Strategy Implementation Research, Journal of Business Research, Vol.45, No.2, pp. 119-134. http://dx.doi.org/10.1016/S0148-2963(97)00231-2

Noble, C.H., and Mokwa, M.P. (1999). Implementing Marketing Strategies: Developing and Testing a Managerial Theory, Journal of Marketing, Vol.63, pp. 57-63. http://dx.doi.org/10.2307/1251974

O'Regan, N., and Ghobadian, A. (2002). Formal Strategic Planning: A Key to Effective Business Process Management? Business Process Management Journal, Vol.8. No.5, pp. 416-429. http://dx.doi.org/10.1108/14637150210449102

Parnell, J. (2006). Generic Strategies After Two Decades: A Reconceptualization of Competitive Strategy, Management Decision, Vol.44, No.8, pp. 1139-1154. http://dx.doi.org/10.1108/00251740610690667

Pearce, J., and Robinson, R. (2002). Strategic Management. McGraw-Hill, Boston.

Pearce, J.A., and Robinson, Jr. R. B. (2005). Strategic Management: Formulation, Implementation and Control, Business Week, 9th Edition, McGraw-Hill Companies Inc., New York, N.Y. pp. 7-9; 12; 29; 131-132; 166.

Pearce, J. A., and Robinson, Jr. R. B. (2007). Formulation, Implementation and Control of Competitive Strategy, 10 ${ }^{\text {th }}$ edition, Chicago, IL, Richard D. Irwin. 
Philips, P., and Appiah-Adu, K. (1998). Benchmarking to Improve the Strategic Planning Process in the Hotel Sector, Services Industries Journal, Vol. 18, No. 1, pp.1-18. http://dx.doi.org/10.1080/02642069800000001

Piercy, N.F. (1998). Marketing Implementation: The Implications of Marketing Paradigm Weakness for Strategy Execution Process, Journal of the Academy of Marketing Science, Vol.26, No.3, pp. 222-236. http://dx.doi.org/10.1177/0092070398263004

Porter, M. (1980). Competitive Strategy: Techniques of Analyzing Industries and Competitors. The Free Press, New York, N.Y.

Rogers, A., and Smith, M.K. (2006). Evaluation: Learning What Matters, Rank Foundation/YMCA George Williams College, London.

Sashittal, H.C., and Jassawalla, A.R. (2001). Marketing Implementation in Smaller Organizations: Definition, Framework and Propositional Inventory, Journal of the Academy of Marketing Science, Vol.29, No.1, pp. 50-69. http://dx.doi.org/10.1177/0092070301291004

Shaw, G., Brown, R. and Bromiley, P. (1998). Strategic Stories: How 3M is Rewriting Business Planning, Harvard Business Review, Vol.76, No.3, pp.41-50.

Snyman, R., and Kruger, C.J. (2004). The Interdependency between Strategic Management and Strategic Knowledge Management, Journal of Knowledge Management, $\quad$ Vol.8, $\quad$ No.1, pp. 5-19. http://dx.doi.org/10.1108/13673270410523871

Smith, M. K. (2001, 2006). Evaluation, in the Encyclopaedia of Informal Education www.infed.org/biblio/b-eval.htm

Steiner, G. (1979). Strategic Planning: What every manager should know, Free Press, New York, NY.

Stoney, C. (2001). Strategic Management or Strategic Typology? A Case Study into Change within a Local U.K. Local authority. The International Journal of Public Sector Management, Vol.14, No.1, pp. $27-42$. http://dx.doi.org/10.1108/09513550110387057

Thompson Jr., A.A., and Strickland III, A.J. (2001). Crafting and Executing Strategy; Text and Cases. Mc-Graw-Hill/Irwin, New York, N.Y, pp.3; 34; 55-56; 365.

www.uccghana.net/Admin/Strategic_Plan.htm (cited 8/3/2006)

www.bc.edu/bc_org/avp/soe/cihe/profiles/Ghana.htm (cited 9/4/2006)

http://home.att.net/ nickols/strategy_defn.htm (cited 19/1/2003)

http://homeatt.net/ nickols/strategy_defn.htm (cited, 19/1/2003)

http://www.agecon.purdue.edu/staff/gray/extension/strategic (cited, 17/11/2006)

http://www.weresearchit.co.uk.evaluation_theory.htm

\section{Further Reading}

Annual Report (2007), University of Ghana Annual Report, Legon.

Anthony, N., and Govindarajan, D. (2004). Management Control Systems, 11th Edition pp.54; 56-57.

Ansoff, H. I. (1986). Corporate Strategy, McGraw-Hill, New York.

Arnoldo, H. (1990). Redefining the Concept of Strategy and the Strategy Formation Process, Planning Review, pp. 34-40.

Bartol, K.M., and Martin, D.C. (1991). Management, McGraw-Hill, Inc., New York.

Basic Statistics (2006), University of Ghana Basic Statistics, Legon. 16-18; pp.3; 5-7.

Basic Statistics (2006), University of Cape Coast Basic Statistics, 54-55; 57; pp.17-47.

Basic Statistics (2006), Kwame Nkrumah University of Science and Technology, Basic Statistics, Kumasi, pp.9; 20 25-26.

Bennet, R. (1996). Corporate Strategy and Business Planning, Pearson Education Limited, Great Britain, pp.4.

Bonn, I. (2001). Developing Strategic Thinking as a Core Competency. Management Decision, Vol.39, No.1, pp. 63-70. http://dx.doi.org/10.1108/EUM0000000005408 
Carter, H. (1999). Strategic Planning Reborn, Work Study, Vol. 48, No.2, pp. 46-48. http://dx.doi.org/10.1108/00438029910259062

Collis, D. J., and Montgomery, C.A. (1998). Creating Corporate Advantage, Harvard Business Review, Vol.76, No.3, pp.71-83.

Davies, W. (2000). Understanding Strategy. Strategy and Leadership, Vol.28, No.5, pp. 25-30. http://dx.doi.org/10.1108/10878570010379428

De Toni, A., and Tonchia, S. (2003). Strategic Planning and Firm's Competencies: Traditional Approaches and New Perspectives, International Journal of Operations and Production Management, Vol.23, No.9, pp.947-976. http://dx.doi.org/10.1108/01443570310491729

Dess, G.G., and Lumpkin, G.T. (2003). Strategic Management, Creating Competitive Advantages, International Edition, McGraw-Hill, Irwin, pp. 154.

Elenkov, D. (1997). Strategic Uncertainty and Environmental Scanning: The Case for Institutional Influences on Scanning Behaviour, Strategic Management Journal, Vol. 18, pp. $287-302$. http://dx.doi.org/10.1002/(SICI)1097-0266(199704)18:4<287::AID-SMJ865>3.0.CO;2-B

Falshaw, J.R., Glaister, K.W., and Tatoglu, E. (2005). Evidence on Formal Strategic Planning and Company Performance, Management Decision, Vol.44, No.1, pp. 9-30. http://dx.doi.org/10.1108/00251740610641436

Farjou, M. (2002). Towards an Organic Perspective of Strategy, Strategic Management Journal, Vol.23, No.7, pp. 561-594. http://dx.doi.org/10.1002/smj.239

Foss, N. J., and Knudson, T. (2003). The Resource-based Triangle: Towards a Sustainable Explanation of Competitive Advantage, Management Decision Economics, Vol.24, pp. 291-307. http://dx.doi.org/10.1002/mde.1122

Glass, N.M. (1991). Pro-active Management: How to Improve your Management Performance, Nichols Publishing, East Brunswick N. J.

Gorski, S.E. (1991). The SWOT Team: Focusing on Minorities, Community, Technical, and Junior College Journal, Vol.61, No.3, pp. 30-33.

Gibson, J. L., Ivancevich, J.M., and Donnelly, J.H. (1997). Organizations: Behaviour, Structure and Processes. McGraw-Hill Companies, USA. pp.15-17.

Hopkins, W.E., and Hopkins, S.A. (1997). Strategic Planning-Financial Performance Relationships in Banks: A Causal Examination, Strategic Management Journal, $\quad$ Vol.18, $\quad$ No.8, $\quad$ pp. $635-652$. http://dx.doi.org/10.1002/(SICI)1097-0266(199709)18:8<635::AID-SMJ904>3.0.CO;2-\#

Kim, E., Nam, D., and Stimper, J.L. (2004). The Applicability of Porter's Generic Strategies in the digital age: Assumptions, Conjectures, and Suggestions, Journal of Management, Vol.30, pp. 569-590. http://dx.doi.org/10.1016/j.jm.2003.12.001

Kumura, S., and Mourdoukoutas, P. (2000). Effective Integration of Management Control Systems for Competing in Global Industries, European Business Review, Vol.12, No.1, pp. 41-45. http://dx.doi.org/10.1108/09555340010307558

Mintzberg, H. (1991). The Effective Organization: Forces and Forms, Sloan Management Review, Vol.32, No.2, pp.54-67.

Mintzberg, H., and Lampel, J. (1999). Reflecting on the Strategy Process, Sloan Management Review, Vol.40, No.3, pp. 21-30

Okumus, F. (2003). A Framework to Implement Strategies in Organizations, Management Decisions, MCB UP Limited, Vol.41, No.9, pp. 871-882.

Pearce, J. A., and Robinson Jr., R. B. (2003). Strategic Management: Formulation, Implementation and Control. 8th Edition, Business Week, McGraw-Hill Companies Inc., New York, N.Y.

Pecotich, A., Purdie, F.J., and Hattie, J. (2003). An Evaluation of Typologies of Marketplace Strategic Actions: The Structure of Australian Top Management Perceptions, European Journal of Marketing, Vol.37, No.34, pp. 498-529. http://dx.doi.org/10.1108/03090560310459069

Porter. M. (1985). Competitive Advantage: Creating and Maintaining Superior Performance, The Free Press, New York, N.Y. 
Porter. M. (1991). Towards A Dynamic Theory of Strategy, Strategic Management Journal, Vol.12, pp. 95-117. http://dx.doi.org/10.1002/smj.4250121008

Porter, M. (1996). What is Strategy? Harvard Business Review, pp. 61-78.

Porter, M. E. (1998). Competitive Strategy: Techniques for Analyzing Industries and Competitors, The Free Press, New York, N.Y.

Saunders, M. (1997). Lewis P. and Thornhill A., Research Methods for Business Students, Pitman, London.

University of Ghana Statutes (2004). The Statutes of the University of Ghana, Ghana Universities Press, Legon. Vol 24/52, pp. 2-6.

Zou, S., and Cavusgil, S.T. (1996). Global Strategy: A Review and an Integrated Conceptual Framework, European Journal of Marketing, Vol.30 No.1, pp. 52-69. http://dx.doi.org/10.1108/03090569610105799

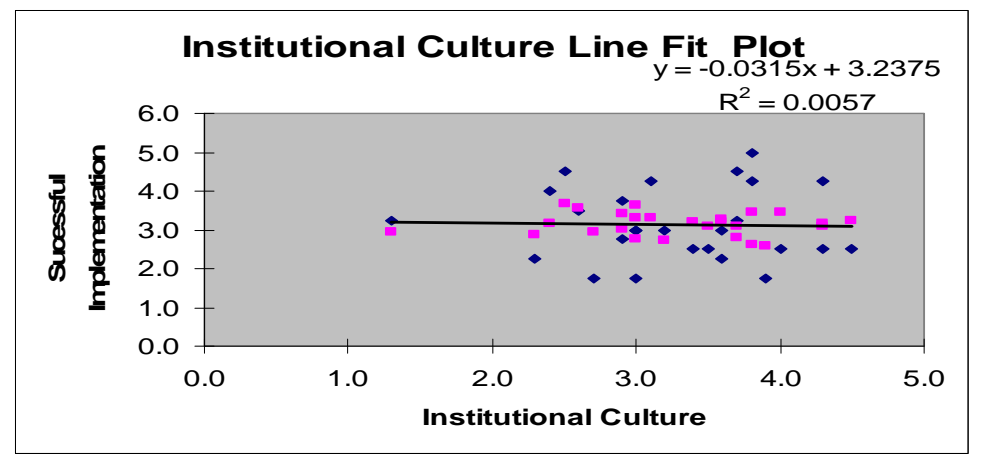

Figure 1. Relationship B/N Institutional Culture and Successful Implementation (UCC) Source: Field Work (2007)

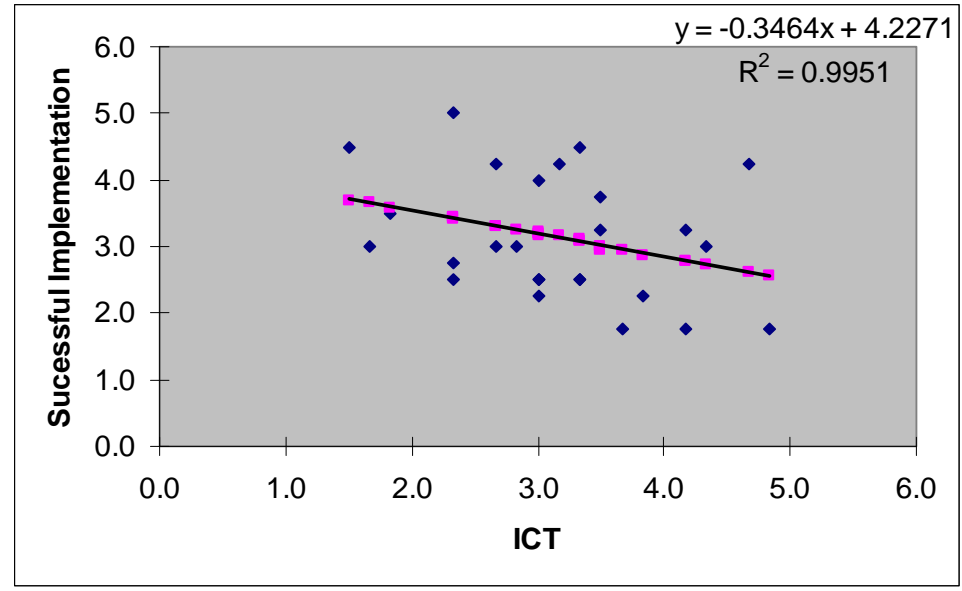

Figure 2. Relationship Between ICT And Successful Implementation (UCC)

Source: Field Work (2007) 


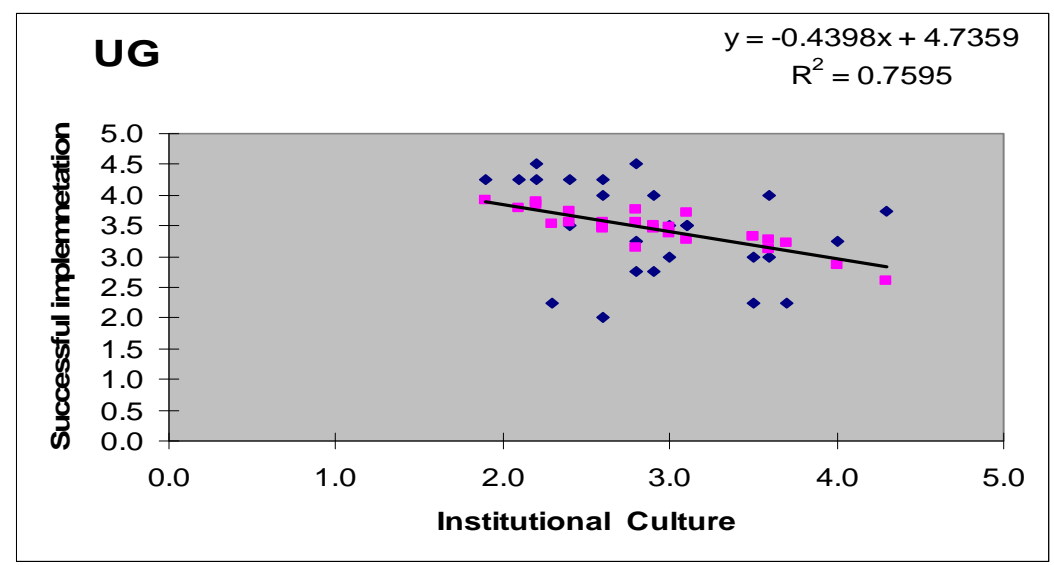

Figure 3. Regression for Institutional Culture on Successful Implementation Source: Field Work (2007)

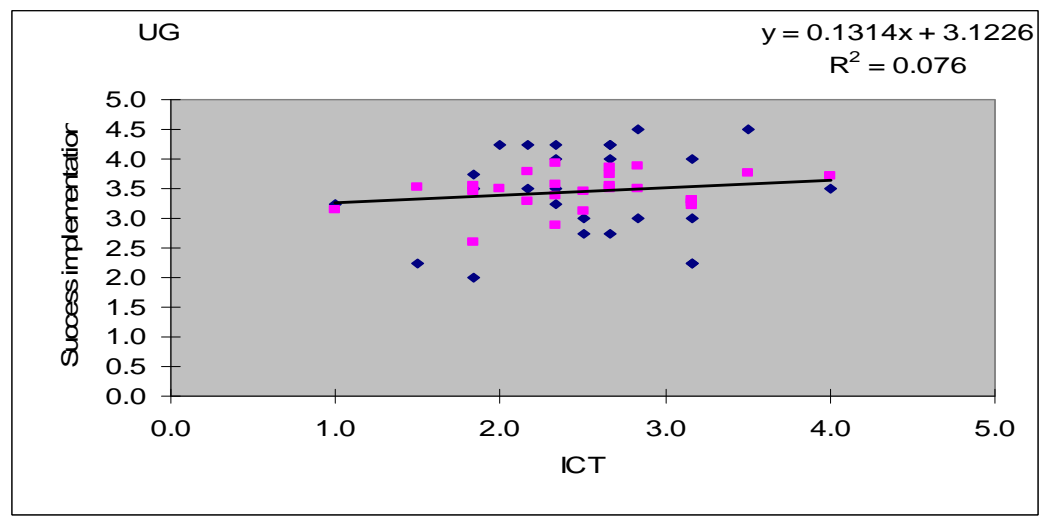

Figure 4. Regression For ICT On Successful Implementation At UG Source: Field Work (2007)

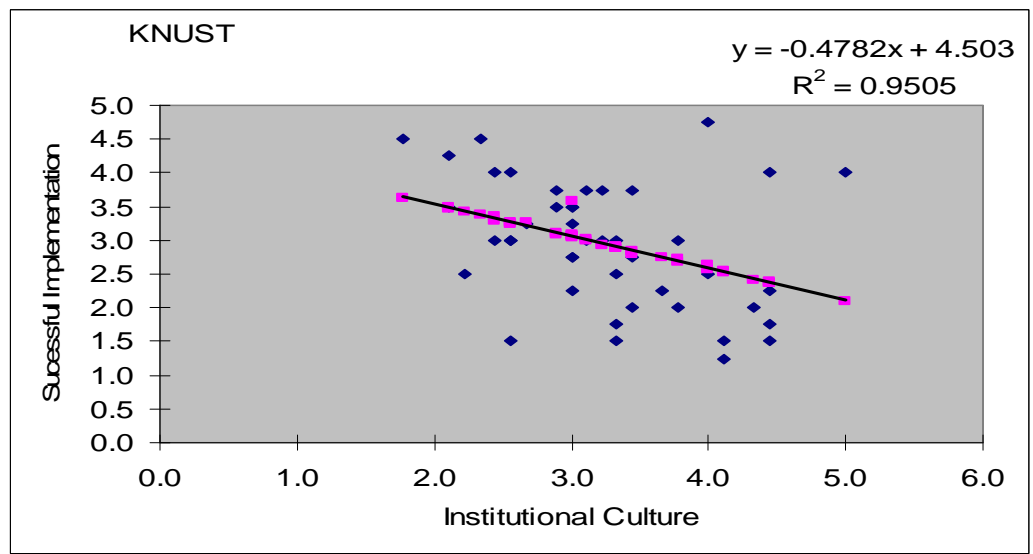

Figure 5. Regression for Institutional Culture on Successful Implementation Source: Field Work (2007) 


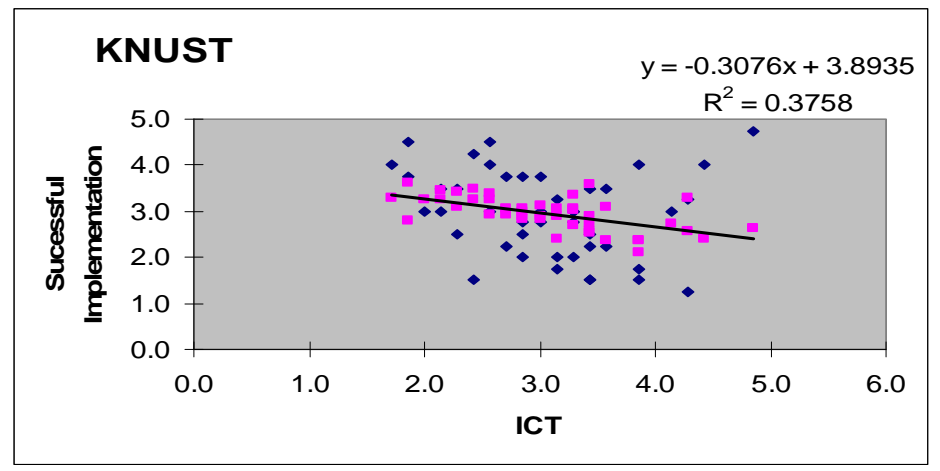

Figure 6. Regression for ICT on Successful Implementation Source: Field Work (2007)

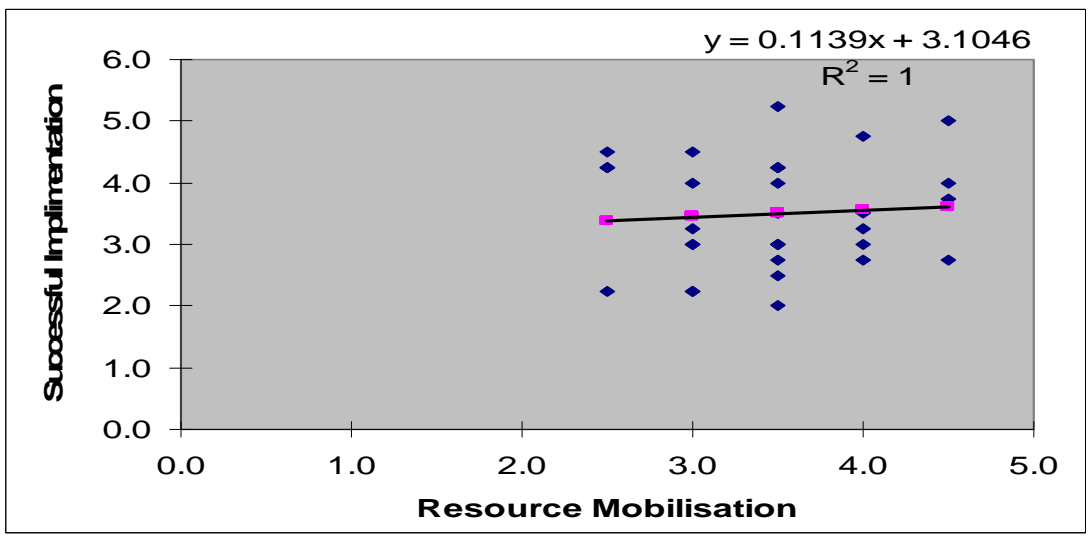

Figure 7. Regression for Resource Mobilization in Public Universities Source: Field Work (2007) 